\title{
Synthesis of the equipment health management system of the turbine units' of thermal power stations
}

\author{
Batyrbek A. Suleimenov ${ }^{1}$, Laura A. Sugurova ${ }^{2,}$, Alibek B. Suleimenov ${ }^{1}$, Aituar B. Suleimenov ${ }^{1}$, and \\ Oxana V. Zhirnova ${ }^{1}$ \\ ${ }^{1}$ Kazakh National Technical University named after Satpayev K.I., Almaty, Kazakhstan \\ 2 Taraz State University after M. Kh Dulati, Taraz, Kazakhstan
}

Received: 13 October 2016 / Accepted: 7 December 2017

\begin{abstract}
The aim of the research is the development of technical diagnostics subsystem with the possibility of its further integration into the automated system of equipment health management, which will improve the efficiency of data ware, hardware and software. Synthesis of intellectual diagnostic models was produced a by using the Matlab graphical agents. At the same time, there were synthesized models of three types: fuzzy, neural-network and model built by planning the full factorial experimental method. Was proposed the concept of the three-stage procedure of the diagnosis of the thermal power station's turbine unit, instead of the creation of diagnosis mathematical models and failure models of objects, immediately begin to develop an algorithm of diagnosis using advanced intelligent technologies. The technique of creating a sub-line diagnostics status of the turbine unit, which includes three main stages: identification of diagnostic features based on expert method; the synthesis of diagnostic model of the facility technical condition; research models on the stability, sensitivity and uniqueness, was proposed. The main diagnostic features of assessing the state of turbine equipment, which, in accordance with the concept developed, allow forming a matrix of planning a full factorial experiment. The proposed techniques and concepts were subjected to experimental verification. The intellectual diagnostic model of turbine unit equipment health was proposed, synthesized and investigated. It was found that the best model is the model, built using neuro-fuzzy algorithms. The simulation was provided for neuro-fuzzy algorithms and confirmed their effectiveness and compliance with the laws of the physical functioning of the HPC. The results of this research have been used in the development of Almaty CHP-2 turbine equipment health management subsystems, allow the further development of the theoretical foundations of intellectual systems, and demonstrate the possibility of using modern concepts to solve important technical problems. Subsystem of operative diagnosis and the following software implementation in a complex of automated technological process of thermal power control system allows one to make an early diagnosis of the equipment health. This significantly reduces the maintenance costs, improves reliability and security, as well as the effectiveness of the control system. In this regard, the results of this study provide further development of the theoretical foundations of the intellectual systems and demonstrate the possibility of modern concepts usage to determinate the important technical problems.
\end{abstract}

Keywords: Equipment health management / a full factorial experiment / expert systems / fuzzy systems / intellectual technology / neural-network models / neuro fuzzy algorithms / technical diagnostics / thermal station / turbine unit

\section{Introduction}

For the current moment, the Energetics is characterized by the intensification of the use of facilities and installed equipment resources. The amount of equipment, which has worked for over 25 years, is about $50 \%$ or more $[1,2]$. Therefore, there is a natural aging process of equipment in

\footnotetext{
* e-mail: batyrbek.suleymenov@gmail.com
}

thermal power stations in almost all countries [3]. In this regard, the problem of diagnosis of its equipment health is one of the priorities in the power sector.

An important element of the operation and maintenance of turbines is the uninterrupted control of its operating condition. It is necessary to take into account the technical control requirements - in a timely manner to determine the actual condition of the object (in good, valid, pre-emergency and emergency), and effectively detect and remove the arising defects. The timely implementation of correct decisions to eliminate defects provides high 
availability, reduces downtime, declines the repair costs, extend the life of turbine equipment [4-6]. This can be achieved by intellectual diagnostic of conditions and the operating modes of the equipment.

To solve the problems of diagnostics of complex technical systems with a large number of possible defects is necessary to develop mathematical models, methods and algorithms for the effective detection of defects that are applicable not only in a specific application domain, but having a common property for a large class of technical systems. Diagnosis of the turbine units of thermal power stations and the development of a common methodology to assess their condition, refer to [7-9] the created valuation techniques are based on models [10,11], the monitoring pattern is discussed in Liu et al. [12], the economic component of the risk of turbine damage is described in detail in Carcasci et al. [13] and Sisi et al. [14]. Diagnostics of equipment health management man-made risk is studied in numerous works $[15,16]$.

Having the effective instrumental the calculation methods and diagnostic agents make it possible to operate the units for the actual equipment health. For today, in the following operating conditions such diagnostic types are used: parametric, vibration, the analysis of used oil, optical and acoustic methods for inspection of turbine units and components $[17,18]$.

These mentioned methods require fairly sophisticated instruments, measurement procedures and analysis of diagnostic signs with the need to develop complex mathematical descriptions of diagnostic facilities. In addition, almost all of the methods listed above aren't intended for the automated synthesis of operational diagnostic systems as part of the existing automatic systems of equipment health management and control.

At the same time, the use of information support of the existing automated systems of technical control allows to create the diagnostic systems, taking into account a large number of measured variables (diagnostic indicators) to assess the condition of the object of diagnosis. This intensely reduces the cost to create the automated operative diagnostics systems, since the information capabilities of an existing system are used.

Operative diagnostics subsystems as part of the current systems of technical control allow using in their algorithms the efficient diagnosis methods: vibration diagnostics, parametric diagnostics and, if it is necessary, and the method of phase trajectories. However, the qualitative (not quantitative) assessment of signs and causes of malfunction do not allow the "calculate" estimate of the proximity to the specific situation of emergency. For the calculation of such an assessment, it is necessary to develop a mathematical model of the diagnosis object functioning and to create a mathematical model of damages and letdowns, as well as to build a diagnosis algorithms $[19,20]$.

The IT usage, in particular, neural-networks [21-23] is one of the important research directions in the field of the technical objects' diagnostics. This suggests that the complexity of the control object determines the use of more innovative approaches in solving the problems of monitoring and diagnosis of the condition and then making decisions and issuing recommendations.
A number of quantitative indicators estimates the level of diagnosing of an equipment health: accuracy; compliance with the parameter obtained in the diagnosis, its actual value; the accuracy, the minimum probability of diagnosing errors; speed; costs [24-26].

The development of the operative diagnostics subsystems and the following software implementation in a complex of automated systems of technical control of thermal power stations can significantly reduce repair costs, improve reliability and operational safety, as well as improve the efficiency of the control system.

The results of this study were tested at the turbine unit of PT-80/100-140 Almaty CHP-2, allow the further development of the theoretical foundations of intellectual systems, and demonstrate the possibility of using modern concepts to solve important technical problems.

The growth of the degree of the decision-making responsibility on the time display of equipment for repair has tightened the requirements for the quality of the identification of the models, which are based on information obtained in the diagnosis of turbine condition. Their implementation in the conditions of the old maintenance forms on the system of preventive maintenance has become ineffective. There appears to be a lack of adequate diagnostic models and models of decisionmaking on the withdrawal of turbine to repair or reduce the load. Optimization of management decisions, to ensure operational control and diagnostics of equipment health for structural-complex systems is an urgent problem.

Having the effective instrumental the calculation methods and diagnostic agents allows operating the units for the actual equipment health. This provides a higher level of machine reliability and significantly reduces the costs, associated with the scheduled preventive maintenance work, reducing the need for spare parts and maintenance staff, increases the quality of the repair.

The aim of the work is to develop technical diagnostics subsystem with the possibility of its further integration into the operating control system. This will improve the efficiency of dataware, hardware and software. To achieve this aim, the problem of technical diagnostics is solving based on the use of intellectual technologies and models of full factorial experiment.

\section{Research methods}

\subsection{Three-stage procedure for creating a diagnostic system}

On the first stage with the help of experienced experts by ranking from the general list of all diagnostic features are determined those, which are, according to experts, essential for assessment of the equipment health management. The main task of the first stage is the drawing up of a planning matrix of a full factorial experiment (FFE). The FFE planning matrix usage creates the intellectual diagnostic model equipment health management. Herewith, for the three-level factors the total number of possible combinations of factors at the two input variables is equal to $N=3^{2}=9$, for the three variables $-3^{3}=27$, etc. 


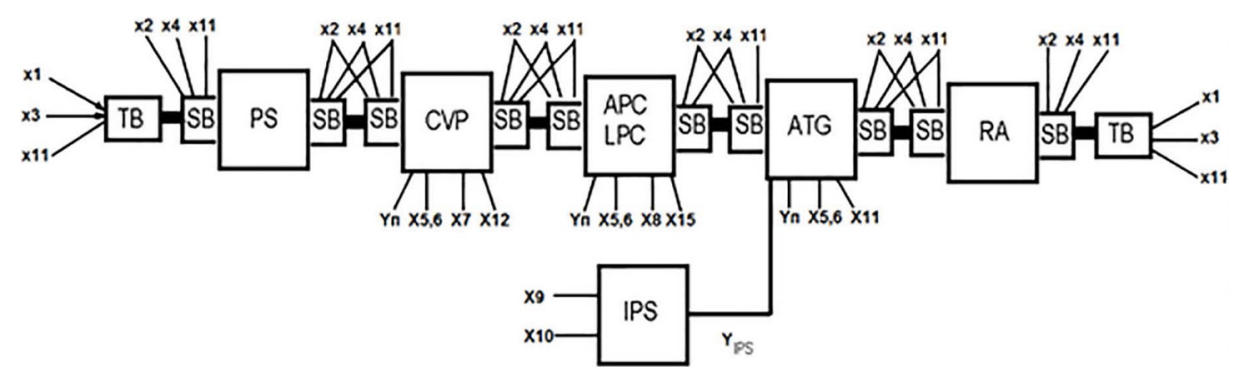

Fig. 1. Elements of the turbine unit and the effect of diagnostic signs on their equipment health.

Formation of the FFE planning matrix with the help of experts greatly accelerates and reduces the cost of this procedure. Experts carried out the so-called "thought experiments" instead of expensive, conducted active experiments. In addition, it should be kept in mind that conducting active experiments in conditions of the current production is impossible due to possible emergencies, when the variable of the process change from the minimum value to their maximum values, and vice versa. In addition, many enterprises simply do not have the ability to change the variables according to the matrix of FFE planning.

It must be highlighted that the output values $\mathrm{Y}_{\mathrm{i}}$ are actually equipment health evaluation of the object, so FFE planning matrix displays diagnostic model for all, planned by experts, combinations of input variables (diagnostic signs).

On the third stage, is synthesized the research of the intellectual diagnostic model for stability, adequacy, sensitivity and uniqueness.

\subsection{Almaty CHP-2 technical equipment}

The steam turbine PT-80 (produced by LMZ - Leningradsky Metallichesky Zavod a division of the "Power Machines" company) is a single-shaft two-cylinder unit, designed for direct drive generator. The authors of this article propose to consider turbine as a set of the following main elements located on the same shaft: support bearing (SB); cylinder and high-pressure rotor (HPC); cylinder and low pressure rotor (LPC); alternator (ATG); thrust bearing (TB). In addition, due to the particular dangers the authors propose to consider the hydrogen supply system (IPS) in the generator housing as a separate component that is not associated with the other single-shaft (Fig. 1).

The development of effective methods of control of technological parameters of the power station during the exploitation period, detection of defects and faults at an early stage of their occurrence, as well as the definition of a remaining resource is very relevant assessment of equipment health management of potentially hazardous elements of the technical system. Diagnosis success is largely due to the correctness of the choice of informative parameters for the construction of the principal diagnostic models and object recognition and identification of measuring systems models.

However, the question of recognition of difficultdistinguishable faults on a quantitative and qualitative assessment of functional and vibration parameters has not solved yet. Therefore, considered in this study issues of improving the information content of defect identification criteria in the turbine unit is an actual scientific task. Of course, solving of the diagnostics problems requires the modern systems of automatic control and regulation of the boiler and turbine units, systems for collecting and processing information.

The technique of creating operating diagnostics of the turbine unit conditions includes three main stages: identification of diagnostic features based on expert method; the synthesis of diagnostic model of equipment health; research models on the stability, sensitivity and uniqueness.

In order to implement the proposed three-stage procedure for creating diagnostic subsystem in the case of turbine we conducted a survey of operators, engineers and technical workers of the Almaty CHP-2 turbine manufactory, which showed that the main variables that characterize the condition of the turbine unit in general are the following: $\mathrm{X}_{1}-$ vibration of the thrust bearing; $\mathrm{X}_{2}$ - vibration of the support bearing; $\mathrm{X}_{3}-$ Babbitt thrust bearing temperature; $\mathrm{X}_{4}-$ Babbitt support bearing temperature; $\mathrm{X}_{5}$ - axial shift in the direction of the generator; $\mathrm{X}_{6}-$ axial shift towards the chair; $\mathrm{X}_{7}-$ the relative expansion of the high-pressure rotor; $\mathrm{X}_{8}$ - the relative expansion of the low-pressure rotor; $\mathrm{X}_{9}$ - the hydrogen pressure in the generator frame; $\mathrm{X}_{10}$ - the temperature in the hydrogen generator frame; $\mathrm{X}_{11}-$ the oil temperature after the oil cooler; $\mathrm{X}_{12}$ - the pressure in the discharge chamber of high-pressure cylinder; $\mathrm{X}_{13}$ - steam temperature; $\mathrm{X}_{14}$ - steam pressure; $\mathrm{X}_{15}$ - the fall of the vacuum in the condenser; $\mathrm{X}_{16}$ - metal temperature in a highpressure cylinder; $\mathrm{X}_{17}$ - metal temperature in the lowpressure cylinder.

All of these variables are controlled by the appliances of the manufactory service, which makes it possible to synthesize the automated system of the operative diagnostic of turbine CHP equipment health.

Next, there must be created the FFE planning matrix for the synthesis of intellectual model of diagnosis and prognosis. However, in this case, there is a need to spend a huge amount of "thought" experiments, for example, for 3level assessment the number of data points will be $N=3^{17}$, which is absolutely impossible to implement. In this regard, it is necessary to decompose the task of forming the FFE planning matrix. To this end, we offer to evaluate the effect of diagnostic features (DF): $\mathrm{X}_{1}-\mathrm{X}_{17}$ on the condition of not just the turbine unit in general and its individual main parts that will reduce the impact of the "curse of dimensionality" on the formation of FFE matrix. 
Figure 1 shows that the vibration, Babbitt temperature and oil temperature, influence the equipment health of the bearing, herewith, the evaluation of the equipment health of the 10 bearings (Yop and Yup), in turn, are the diagnostic features for the evaluation of the equipment health of HPC, LPC and ATG. It is necessary to consider the fact that these elements are equally affected by the turbine condition as a support and thrust bearings. In this regard, it is proposed to take into account assessment of the equipment health of only one of the 10 bearings having a worst-case assessment of the value (denoted by the value of this evaluation through $\mathrm{Y}_{\mathrm{b}}$ ).

Accounting for a general assessment of the equipment health of the bearings $\left(Y_{b}\right)$ will reduce the number of diagnostic features per unit for each of the three basic elements: HPC, LPC and ATG. Evaluation of equipment health of the most dangerous hydrogen supply system $\left(\mathrm{Y}_{\mathrm{hss}}\right)$ depends on hydrogen pressure and temperature in the generator frame. At the same time, $\mathrm{Y}_{\mathrm{hss}}$ in conjunction with other diagnostic features $\left(\mathrm{X}_{5,6}, \mathrm{Y}_{\mathrm{n}}\right.$ and $\left.\mathrm{X}_{11}\right)$ can serve as baseline data for the evaluation of the equipment health of the generator in general.

Herewith, the axial shift towards the generator $\left(\mathrm{X}_{5}\right)$ and the axial shift towards the chair $\left(\mathrm{X}_{6}\right)$ are mutually exclusive factors. Shift can be carried out either in one or the other way, so the authors combined these two factors alone $-\mathrm{X}_{5,6}$, which reduced the number of diagnostic features per unit for each of the three basic elements: HPC, LPC and ATG.

In addition, the variables $\mathrm{X}_{16}$ (metal temperature in the high-pressure cylinder) and $\mathrm{X}_{17}$ (metal temperature in the low-pressure cylinder) are diagnostic for assessing the equipment health of HPC and LPC only in the process of their preparation for launch during heating. During the normal operation of the turbine unit a person does not control them, so the authors of this paper were excluded from the number of diagnostic features, thereby further reducing the dimension of the problem being solved.

Variables $\mathrm{X}_{13}$ (steam temperature) and $\mathrm{X}_{14}$ (steam pressure) are purely technological, depending on the physical condition of steam coming from the boiler manufacture. According to these variables, it is not possible to evaluate the equipment health of the HPC or LPC, so authors also excluded them from the number of diagnostic features.

Thus, taking into account reductions in diagnostic features, evaluation of each of the main elements of the turbine unit can only be estimated by the four diagnostic criteria (Fig. 1), thereby the number of "thought" experiments for each of the parts of the turbine unit (HPC, LPC and GTP) will be $N=3^{4}=81$, which is quite simple to implement.

The basis of the proposed method of development the algorithms of diagnosing is constitute by the FFE planning matrix instead of the traditional rules of productions. Let us consider the method of forming the FFE planning matrix on the example of diagnosing the problem 6 .

Formation of the FFE planning matrix is the most time-consuming and most important operation in the synthesis of intellectual diagnostic models.
The next stage of constructing the fuzzy model is the formation of the rule base (KB), by means of a survey of experienced technology operators worked for a long time as a machinist (operators) of Almaty CHP-2 turbine type PT-80 / 100-140. The survey allowed making the rules as a FFE planning matrix with step interval of 0.5 , a detail of which is given in Table 1 . The quality of the knowledge base (Table 1) will depend on the quality and efficiency of the models (algorithms) of diagnostics of HPC (Highpressure cylinder) equipment health. The number of mental experiments, herewith, will be $N=34=81$, as the number of input variables is equal to 4 , with 3 -level values: $0.0,0.5$ and 1.0 .

Synthesis of intellectual models of the HPC condition diagnosis was produced using the Matlab graphical agents. At the same time, there were synthesized the models of three types: fuzzy, neural-network and neuro fuzzy and model built by experimental design. Then with the help of these four models there were calculated every 81 data points. Comparative results of modeling with four different algorithms are shown in Tables 2 and 3 .

The most effective scheme for the modeling of the equipment health are the neural networks [23-25]. Neural networks allow to solve the problem of classification and to assess the condition of the object in a small number of training steps. Probabilistic neural network gives the best result, allows solving the problem in fewer steps and with higher accuracy. Therefore, it is necessary to explore the possibilities of both the neural networks, and the models of uncertainty accounting in order to increase the efficiency of processes for detecting defects or deviations.

\section{Results and discussion}

The obtained results showed that the use of intellectual models and the apparatus of fuzzy neural networks, unlike the design of experiments methods, would allow to evaluate the risks of failure of the turbine generator based on the live data.

Further studies on the stability, sensitivity and uniqueness are held only for the optimal model - the neuro fuzzy.

Sensitivity means that a small change in the input parameters occur the change of indicator system properties that can be found in a calculation error. The purpose of sensitivity analysis is a comparative analysis of the impact of various factors on the result of the decision of modeling tasks.

A detailed diagram of the sensitivity analysis:

- selection of factors, minor change of which can be significant in terms of impact on the researcher's result;

- the establishment of the nominal and limit (upper and lower) values of selected factors;

- decision of the modeling tasks in different ranges of input data for all the selected limit values of factors;

- construction of the dependency in sensitivity solving of the problem for all the factors and changes in the source data range.

Figure 2 shows the assessment results of sensitivity in a change of 4 input variables on the value of 0.02 . 
Table 1. FFE planning matrix.

\begin{tabular}{llllll}
\hline Input data & \multicolumn{2}{c}{} & Output data \\
\hline & $\mathrm{Y}_{\mathrm{n}}$ & $\mathrm{X}_{5,6}$ & $\mathrm{X}_{7}$ & $\mathrm{X}_{12}$ & $\mathrm{Y}_{\mathrm{HPC}}$ \\
1 & 0.0 & 0.5 & 0.0 & 0.5 & 0.76 \\
2 & 0.5 & 0.5 & 0.0 & 0.5 & 0.7 \\
3 & 1.0 & 0.5 & 0.0 & 0.5 & 1 \\
4 & 0.0 & 0.0 & 0.0 & 0.5 & 0.24 \\
5 & 0.5 & 0.0 & 0.0 & 0.5 & 0.55 \\
6 & 1.0 & 0.0 & 0.0 & 0.5 & 1 \\
79 & 0.0 & 1.0 & 1.0 & 1 & 1 \\
80 & 0.5 & 1.0 & 1.0 & 1 & 1 \\
81 & 1.0 & 1.0 & 1.0 & 1 & 1 \\
\hline
\end{tabular}

Table 2. Comparative results of modeling.

\begin{tabular}{lllll}
\hline $\mathrm{N}$ & Neuro fuzzy network & Fuzzy logic & Neural-network & Correct answer \\
\hline 1 & 0.76 & 0.69562 & 0.76 & 0.76 \\
2 & 0.68 & 0.90275 & 0.79 & 0.7 \\
3 & 0.97 & 0.97416 & 1 & 1 \\
4 & 0.23 & 0.75911 & 0.249 & 0.24 \\
5 & 0.54 & 0.91648 & 0.559 & 0.55 \\
- & - & - & - & - \\
6 & 0.97 & 0.97805 & 1 & 1 \\
79 & 0.97 & 0.99428 & 1 & 1 \\
80 & 0.97 & 0.97275 & 1 & 1 \\
81 & 0.97 & 0.99508 & 1 & 1 \\
The absolute error & $0.88102 \%$ & $1.15101 \%$ & $1.146136 \%$ & 1 \\
\hline
\end{tabular}

Table 3. Summary table comparing the results for different methods.

\begin{tabular}{ll}
\hline Modeling method & $\begin{array}{l}\text { The value of the } \\
\text { absolute error\% }\end{array}$ \\
& Y \\
\hline 1. Fuzzy algorithms & $1.15101 \%$ \\
2. Neural-network algorithms & $1.146136 \%$ \\
3. Neuro fuzzy network & $0.88102 \%$ \\
4. Experiment planning & $6.75 \%$ \\
\hline
\end{tabular}

Figure 2 shows how a slight change in the input variables 0.02 impact on output variables. Diagnosing the HPC equipment health, the change of input variables 0.02 values on logic and physics of the process should not greatly affect the assessment of the equipment health of CVD due to its insignificance. Figure 2 shows that the curves before and after the change of the input variables to 0.02 is not much different from each other that fully explains and proves the high stability of the neuro-fuzzy diagnostic model of HPC equipment health. This neuro-fuzzy model is more sensitive to the changes of the values of relative expansion of the high pressure rotor $\mathrm{X}_{3}$ and $\mathrm{X}_{2}$ axial thrust in the direction of the generator or the front of the chair.

Let us consider the results of modeling the HPC (Y) equipment health assessment for different values of the input variables $\mathrm{X}_{1}, \mathrm{X}_{2}, \mathrm{X}_{3}$ and $\mathrm{X}_{4}$.

Figure 3 shows the results of modeling for the evaluation of the HPC (Y) equipment health depending on the changes in the general state of the thrust and support bearing $\left(\mathrm{X}_{1}\right)$ for various values of CVD chamber pressures $\left(\mathrm{X}_{4}\right)$, equal to the maximum $\left(\mathrm{X}_{4}=1.0\right)$, medium $\left(\mathrm{X}_{4}=0.5\right)$ and minimum $\left(\mathrm{X}_{4}=0\right)$ values. Modeling was produced at nominal values of the axial offset towards the front of the chair or the generator $\left(\mathrm{X}_{2}=0\right)$ relatively to the expansion of high-pressure rotor $\left(\mathrm{X}_{3}=0\right)$.

Figure 3 shows that the maximum value $(\mathrm{Y}=1)$ of equipment health characteristics the HPC has at maximum values in the general condition of the thrust bearing $\left(\mathrm{X}_{1}=1\right)$ for all values of pressure in the HPC discharge chamber $\left(\mathrm{X}_{4}=0,0.5\right.$ and 1.0). This is understandable because the overall thrust bearing is peer $\left(X_{1}=1\right)$, what is unacceptable and will inevitably entail stopping the turbine unit. When normal presssure in the CVD discharge chamber $\left(\mathrm{X}_{4}=0\right)$ and normal condition of the thrust 


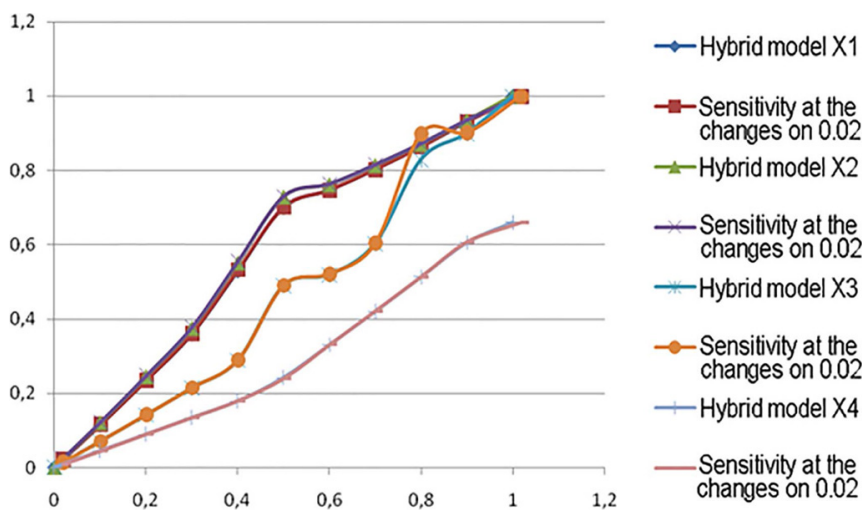

Fig. 2. Neuro fuzzy model sensitivity valuation.

bearing $\left(\mathrm{X}_{1}=0\right)$ the general equipment health of the HPC is the best $(Y=0)$, and when the thrust bearing general equipment health deteriorate to $\left(\mathrm{X}_{1}=0.5\right)$ the overall HPC equipment health is satisfactory $(\mathrm{Y}=0.559)$.

Figure 3 also shows that a moderate value of the pressure in the discharge chamber $\left(\mathrm{X}_{4}=0.5\right)$ characterizes the wear of CVD discharge chamber $\left(\mathrm{X}_{4}=1\right)$. With the best overall bearing equipment health values $\left(X_{1}=0\right)$ general equipment health assessment of HPC is satisfactory $(\mathrm{Y}=0.69)$. It is characterized by the poor condition of the CVD discharge chamber, so it is necessary to reduce the pressure in the CVD discharge chamber by discharge, reducing the supply to the turbine steam in order to prevent further destruction of the discharge chamber. With the overall assessment of the equipment health of the thrust bearing $\mathrm{X}_{1}=0.5$, the overall equipment health of the $\mathrm{HPC}$ equals $\mathrm{Y}=0.759$, which is unacceptable for the long work of turbine unit under these conditions.

From the above it can be concluded that the pressure value, that is the equipment health of the $\mathrm{HPC}$ chamber of high pressure $\left(\mathrm{X}_{4}\right)$ is not critical, so it is always possible to unload the turbine and thereby reduce the rate. In this case, the value of index of the thrust bearing general equipment health is critical for the general state of the turbine unit, due to the impossibility of reducing this indicator during the turbine working.

Figure 4 shows the modeling results of the HPC equipment health valuation $(\mathrm{Y})$ depending on changes in axial thrust values in direction to generator or the front of the chair $\left(\mathrm{X}_{2}\right)$, for different pressures values of $\mathrm{CVD}$ discharge chamber $\left(\mathrm{X}_{4}\right)$, equal to the maximum $\left(\mathrm{X}_{4}=1.0\right)$, medium $\left(\mathrm{X}_{4}=0.5\right)$ and minimum $\left(\mathrm{X}_{4}=0\right)$ values. With nominal values of the relative expansion of the highpressure rotor $\left(\mathrm{X}_{3}=\right)$, and general condition of the support bearing $\left(\mathrm{X}_{1}\right)$.

Figure 4 shows that at the minimum value of pressure in CVD discharge chamber $\left(\mathrm{X}_{4}=0\right)$ the $\mathrm{CVD}$ equipment health worsens with increasing of the axial displacement in the direction of the generator or the front of the chair $\left(\mathrm{X}_{2}\right)$. At $\left(\mathrm{X}_{2}=0.5\right) \mathrm{X}_{4}=0, \mathrm{Y}=0.7$, and when $\mathrm{X}_{2}=1$, $\mathrm{Y}=1$. Almost the same can be seen in the other two curves of values assessment of HPC equipment health, which have different initial data, depending on the pressures in the HPC discharge chamber. At $\left(\mathrm{X}_{4}=0.5\right) \quad \mathrm{X}_{2}=0$, $\mathrm{Y}=0.249$, at $\mathrm{X}_{2}=0.5, \mathrm{Y}=0.729$, when $\mathrm{X}_{2}=1, \mathrm{Y}=1$ and finally at при $\left(\mathrm{X}_{4}=1\right) \mathrm{X}_{2}=0, \mathrm{Y}=0.69$, at $\mathrm{X}_{2}=0.5$, $\mathrm{Y}=0.769$ and at $\mathrm{X}_{2}=1, \mathrm{Y}=1$.

This can conclude that the value of the axial offset towards the front of the chair or the generator $\left(\mathrm{X}_{2}\right)$ is more critical than the pressure in the discharge chamber $\mathrm{X}_{4}$. According to the instructions of the turbine unit maintenance, in increasing of the value of the axial shift in direction of the generator or the front of the chair and the impossibility to normalize within the shortest time the turbine unit switches off. As the axial offset can cause the contact between the stator and the rotor in mind the minimum clearance between them, which can lead to the complete destruction of both the stator and rotor.

In normal operation, the turbine unit axial displacement is relatively stable value. However, in abrupt changes of live steam parameters, this figure goes beyond the established, herewith, the operator immediately takes measures to normalize the steam pressure, supplied to the turbine head by manipulation of control valves in automatic or manual mode with the alert of operators working in parallel of turbine and boiler.

Figure 5 shows how changes the overall assessment of the HPC equipment health (Y), depending on the changes in relative expansion of high-pressure rotor (X3 from 0 to 1 ) and at nominal values of general condition of thrust and support bearings $(\mathrm{X} 1=0)$, the axial shift in direction of the generator or the front of the chair $(\mathrm{X} 2=0)$ and values of pressures in the discharge chamber, which are equal $\mathrm{X}_{4}=0$, $\mathrm{X}_{4}=0.5$ and $\mathrm{X}_{4}=1$.

Figure 5 shows that at the high pressure of different values of the pressure in the discharge chamber $\mathrm{X}_{4}=0$ $\mathrm{X}_{4}=0.5$ and $\mathrm{X}_{4}=1$, the initial point of the curves correspond to the total value of HPC equipment health $\mathrm{Y}=0, \mathrm{Y}=0.249$ and $\mathrm{Y}=0.6$. With an increase in the value of the relative expansion of the high-pressure rotor $\mathrm{X}_{3}$ and the pressures in the high pressure chamber $\left(\mathrm{X}_{4}=0,0.5\right.$ and 1), the value of the overall of the HPC equipment health $(\mathrm{Y})$ tends to 1 . That is, to an emergency condition, when $\mathrm{X}_{4}=0 \quad\left(\mathrm{X}_{3}=0.5 \quad \mathrm{Y}=0.49\right),\left(\mathrm{X}_{3}=1 \quad \mathrm{Y}=1\right)$, at $\mathrm{X}_{4}=0.5$ $\left(\mathrm{X}_{3}=0.5 \mathrm{Y}=0.54\right),\left(\mathrm{X}_{3}=1 \mathrm{Y}=1\right)$ and $\mathrm{X}_{4}=1 \quad\left(\mathrm{X}_{3}=0.5\right.$ $\mathrm{Y}=0.79),\left(\mathrm{X}_{3}=1 \mathrm{Y}=1\right)$.

This can conclude that the value of the relative expansion of the high-pressure rotor $\mathrm{X}_{3}$ is also critical in evaluating the overall HPC equipment health and across the turbine in general. That corresponds to the operating instructions of the turbine unit [25]. The expansion of a high-pressure rotor is accompanied by the same threats that the axial shift towards the generator or the front of the chair, except that in this case the turbine stator expands uncontrollably. The causes of excessive expansion of the high-pressure rotor: the uneven heating of the metal stator and rotor due to the different thickness of the stator and rotor metal. To compensate this phenomenon were provided the flange and studs heating lines and regulation of these flows provides a uniform heating of the metal. In normal work of the turbine this phenomenon is not observed, it occurs only during the starting and stopping of the turbine. 


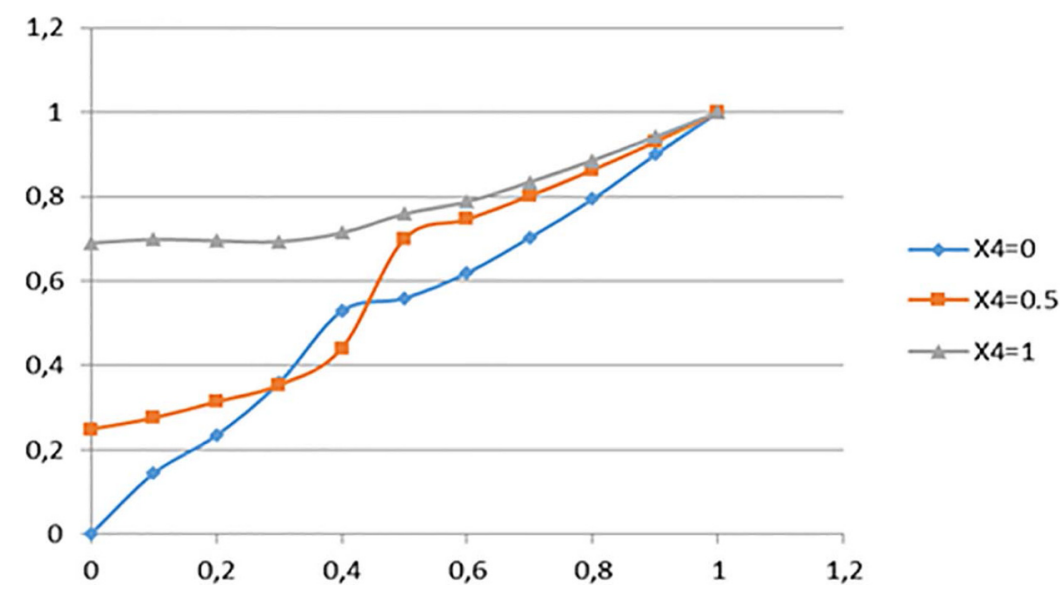

Fig. 3. The modeling results for the assessment of HPC equipment health depending on the changes in the discharge pressure chamber at $\mathrm{X}_{2}=0$ and $\mathrm{X}_{3}=0,5$.

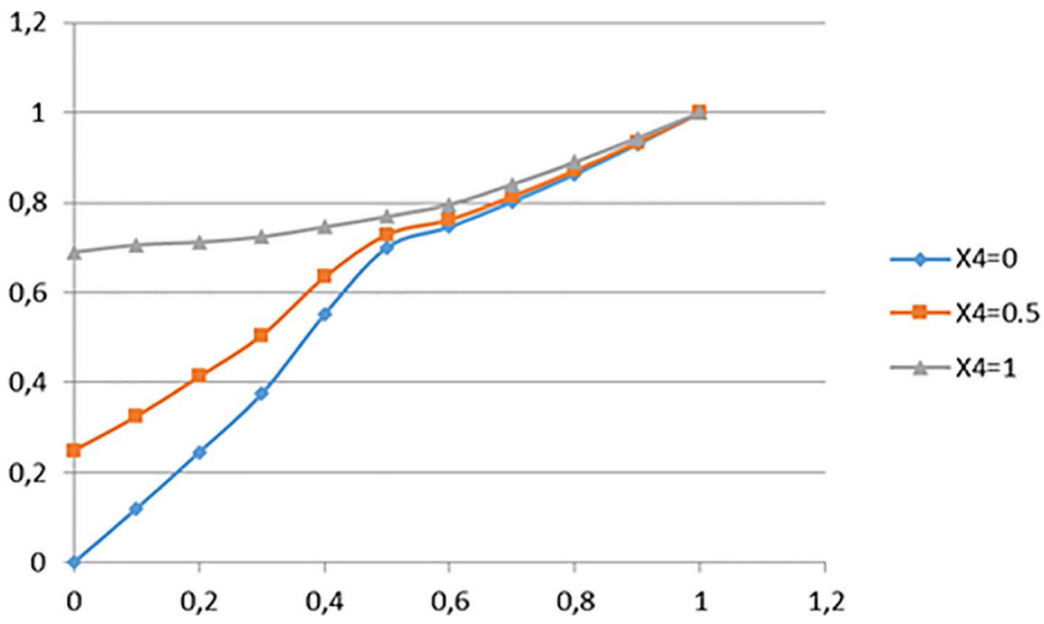

Fig. 4. The modeling results of HPC equipment health valuation (Y) depending on the changes in the axial offset value in direction of the generator or the front of the chairs $\left(\mathrm{X}_{2}\right)$, at $\mathrm{X}_{1}=0$ and $\mathrm{X}_{3}=0$.

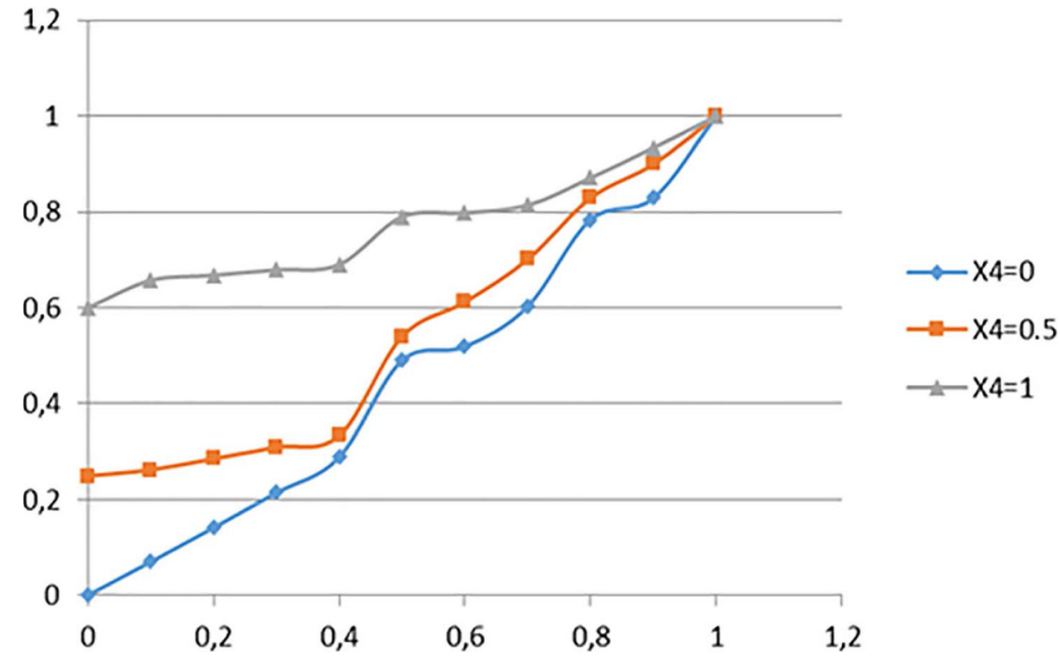

Fig. 5. Modeling results for the assessment of $\mathrm{HPC}$ equipment health $(\mathrm{Y})$, depending on the changes in the relative values of the expansion of the high-pressure rotor $\mathrm{X}_{3}$ at nominal values $\mathrm{X}_{1}=0$ and $\mathrm{X}_{2}=0$. 
The proposed method has been used in the development of subsystem of Almaty CHP-2 turbine equipment health management. Thus, the modeling results of the HPC equipment health valuation are reasonable from the point of view of the physics of PT-80 $\backslash 100-140$ turbine unit technological process and fully reflect the expert judgment - operators of turbine type PT-80 $\backslash 100-140$ and engineering and technical personnel of the turbine Almaty CHP-2 manufacture.

The validity of the obtained modeling results is confirmed by numerous experiments and expert assessments, which were obtained during their analysis. The models reflect the physical processes that is supported by the experiments on sensitivity analyzes. Thus, the use of the developed model allows us to estimate the risk of an accident. It should also be noted that because of the research, was further developed the fuzzy neural network model of classification of the degree of closeness of the current condition to the emergency situation due to the formalization of causality in the analysis of the equipment health of the turbine generator.

\section{Conclusion}

- The analysis of modern diagnostic methods showed that they require rather complex instruments and procedures for measuring and analyzing diagnostic signs with the need to develop complex mathematical descriptions of diagnostic facilities. In addition, almost all of the methods are not appropriate for the synthesis of the automated systems of operative diagnosis as part of the existing automated systems of operate control (PCS).

- Costs for the creation of an automated operative diagnostics system will be reduced considerably, if it will be included in the structure of the existing system of operative control as its subsystems. In this case, the information will be used to ensure the current operative control system that will significantly reduce the cost of its development and implementation. In this case, the effect of the introduction of enhanced operative control system will increase significantly, because in addition to the effects of operative and optimal process control is achieved and the effect of operative diagnostic of technology equipment. In addition, it is possible to expect occurrence of so-called synergistic effect - when the effects of the operative control system and subsystem operational diagnosis is much higher than their simple sum. This is the result of interference of process control and diagnostics of technological equipment on the one hand and optimum operational management process, a positive effect on manufacturing equipment on the other - operative diagnostics enables to save the condition of the operative equipment at the proper level, thereby improving its handling.

- Created on the basis of intellectual technologies subsystems of operative diagnostics, as part of the existing system of operative control allow the use of algorithms in their effective diagnosis methods: vibration diagnostics, parametric diagnostics and, if it is necessary, the method of phase trajectories. Diagnostic functions enable the subsystem to repair the beginning of destructive processes in technological equipment and to locate them in time at an early stage.

- The study proposes the concept of three-stage turbine unit diagnostic procedures, which proposes instead of the creation of mathematical diagnosing models and failure models of objects immediately begin to develop diagnosis algorithm using advanced intellectual technologies.

- The main diagnostic features of assessing the condition of turbine equipment are identified. Diagnostic signs allow, in accordance with the developed concept, to form a FFE planning matrix.

- There is synthesized and investigated the intellectual diagnostic model of turbine unit equipment health. It was found that the best model is the model, built using neurofuzzy algorithms. There was provided the simulation of the neuro-fuzzy algorithms and confirmed their effectiveness and compliance with the laws of the physical functioning of the HPC.

- Subsystem of operative diagnosis and the following software implementation in a complex automated technological process of thermal power control system allows making an early diagnosis of the equipment health. This significantly reduces the maintenance costs, improves reliability and security, as well as the effectiveness of the control system.

- The use of intellectual technologies in the management and decision-making is now a global trend, reflecting the complexity of technical and technological processes in modern industrial systems.

- The results of this research have been used in the development of operative diagnostic subsystems of Almaty CHP-2 turbine equipment health, allow the further development of the theoretical foundations of intelligent systems, and demonstrate the possibility of using modern concepts to solve important technical problems. In this regard, the results of this study provide further development of the theoretical foundations of intellectual systems and demonstrate the possibility of using modern concepts to solve important technical problems.

\section{References}

[1] X. Wu, J. Shen, Y. Li, K. Lee, Steam power plant configuration, design, and control, Wiley Interdiscip. Rev. 4 (2015) 537-563

[2] B.A. Alekseev, Main equipment in power systems. Determining the status (diagnostics) of large turbine units, NTs ENAS, Moscow, 2001

[3] S. Thomas, R. Dawe, Review of ways to transport natural gas energy from countries which do not need the gas for domestic use, Energy 28 (2003) 1461-1477

[4] V.V. Shevchenko, A. Minko, Modernisation of turbogenerators of domestic structures, taking into account the requirements of maintaining their competitiveness, J. NTU "KhPI" 38 (2014) 146-155

[5] Y.-C. Huang, C.-M. Huang, Optimization based support vector classifier for vibration fault diagnosis of steam turbine-generator sets, Procedia Eng. (2012) 1816-1821 
[6] S. Biswas, T. Breuel, Learning morphological transformations with recurrent neural networks. Procedia Comput. Sci. 53 (2015) 335-344

[7] A.M. Pantaleo, S. Camporeale, B. Fortunato, Small scale biomass CHP: techno-economic performance of steam vs. gas turbines with bottoming ORC, Energy Procedia 82 (2015) $825-832$

[8] V.V. Shevchenko, A. Minko, S.A. Lukyanchikova, Proposals to modernize the turbogenerators designs fulfilled a technical resource, J. Sci. Technol. 3 (2015) 8-13

[9] A.I. Kumenko, The improvement modification of rotor unbalance verification technique in monitoring systems and automatic diagnostics. Procedia Eng. 113 (2015) 324331

[10] P. Cross, X. Ma, Nonlinear system identification for modelbased condition monitoring of wind turbines, Renew. Energy 71 (2014) 166-175

[11] I. Antoniadou, G. Manson, W.J. Staszewski, T. Barszcz, A time-frequency analysis approach for condition monitoring of a wind turbine gearbox under varying load conditions, Mech. Syst. Signal Process. 64 (2015) 188-216

[12] W.Y. Liu, B.P. Tang, J.G. Han, X.N. Lu, N.N. Hu, Z.Z. He, The structure healthy condition monitoring and fault diagnosis methods in wind turbines: a review, Renew. Sustain. Energy Rev. 44 (2015) 466-472

[13] C. Carcasci, B. Pacifici, L. Winchler, L. Cosi, R. Ferraro, Thermoeconomic analysis of a one-pressure level heat recovery steam generator considering real steam turbine cost, Energy Procedia 82 (2015) 591-598

[14] G Sisi, P. Liu, L. Zheng, Data reconciliation for the overall thermal system of a steam turbine power plant, Appl. Energy (2016) 165

[15] O. Shindor, A. Svirina, Hydraulic units' vibration diagnostics subsystem improvement and its impact on the level of technogenic risks, Energy Procedia 72 (2015) 345-352
[16] A.M. Pantaleo, P.D. Ciliberti, S.N. Camporeale, Thermoeconomic Assessment of Small Scale Biomass CHP: Steam Turbines vs ORC in Different Energy Demand Segments, Energy Procedia 75 (2015) 1609-1617

[17] V. Shevchenko, I. Lisan, Evaluation of the technical parameters of turbine generators to determine the work to restore them or to establish the need to replace. Systems of arms and military equipment 2 (2015) 145-150

[18] E.V. Urev, J.N. Ahypytova, Problems of Creating technical diagnosis of turbine units, J Thermal Eng 11 (2001) 25-30

[19] V. Uraikul, C.W. Chan, P. Tontiwachwuthikul, Artificial intelligence for monitoring and supervisory control of process systems, Int. J. Eng. Appl. Sci. 20 (2007) 115-131

[20] T. Gavrilova, V. Horoshavskiy, Knowledge base of intellectual systems, St. Petersburg, Piter, 2001 (in Russian)

[21] K. Chen, L. Chen, M. Chen, C. Lee, Using SVM based method for equipment fault detection in a thermal power plant, Comput. Ind. 62 (2011) 42-50.

[22] B. Suleimenov, L. Sugurova, N. Turynbetov, A. Suleimenov, Concept of developing an intelligent system for control and operational diagnostics of technological equipment condition, Informatyka, Automatyka, Pomiary w Gospodarce i Ochronie S rodowiska 1 (2014) 27-34

[23] H. Malik, S. Mishra, Application of probabilistic neural network in fault diagnosis of wind turbine using FAST, TurbSim and Simulink, Procedia Comput. Sci. 58 (2015) 186-193

[24] Y. Li, B. Yang, Z. Wang, X Fault pattern classification of turbine-generator set based on artificial neural network. International Conference 15, 157-159, 2010

[25] K. Lee, J.V. Sickel, J. Hoffman, Controller design for a largescale ultrasupercritical once-through boiler power plant, IEEE Trans. Energy Convers. 25 (2010) 1063-1070

[26] A. Lees, Vibration Problems in Machines: Diagnosis and Resolution, CRC Press, 2016

Cite this article as: A.B. Suleimenov, B.A. Suleimenov, A.B. Suleimenov, L.A. Sugurova, O.V. Zhirnova, Synthesis of the equipment health management system of the turbine units' of thermal power stations, Mechanics \& Industry 19, 209 (2018) 